\title{
Impact of the Nocebo Effect in Clinical Studies of Painful Diabetic Peripheral Neuropathy and Potential Strategies to Minimize this Effect
} Merante $D^{*}$, Currie $A$ and Feins $K$

Daiichi Sankyo Development Ltd. Gerrards Cross, UK

\section{Commentary}

Painful Diabetic Peripheral Neuropathy (PDPN) is a sensory motor polyneuropathy with a diffuse symmetric and length-dependent injury to peripheral nerves that has major implications on quality of life (QOL), morbidity, and costs from a public health perspective.

$16 \%$ of patients with diabetes are affected by PDPN. This complication is frequently unreported (12.5\%) and more frequently untreated (39\%) [1].

Available evidence-based guidelines for treating PDPN address the efficacy of non-pharmacological and pharmacological treatments to reduce pain and improve physical function and QOL in patients [1].

Main pharmacological agents include anticonvulsants, antidepressants, opioids, antioxidants and others. These treatments become often ineffective or lack effectiveness overtime. When pain control is inadequate, combination therapies might be often required.

In addition, current available pharmacological treatments of PDPN are complicated by adverse side effects. The dangers due to severity and duration of side effects by available pain medications are considerable [2]. Typically, the most relevant side effects are CNS-related including somnolence, dizziness, abuse potential, gastrointestinal, cardiovascular, edema, weight gain, ophthalmological disturbances, impotence and increased risk of suicide. These side effects can and do occur at any time during the course of clinical studies, not only in the active medication treatment arm, but also in the placebo arm; they can be severe by intensity and lead to subject discontinuation of treatment.

Traditionally, randomized, double-blind, placebo-controlled studies in PDPN were the gold standard of a clinical study design.

Nowadays, in order to satisfy health outcome regulatory requirements, it has become more relevant to investigate a new treatment by gathering comparative clinical data with currently available and well established active medications investigated as monotherapy or combination treatments. In order to prove that a new investigational drug may be more effective and better tolerated than an existing one, the clinical study design should include an established comparative treatment $[3,4]$.

In the strictest sense, a nocebo response in a clinical trial occurs when subject's symptoms are worsened by the administration of an inert, sham or dummy treatment, called placebo. In comparative clinical studies side effects do not occur only in the active medication treatment arm but, in fact, the nocebo effect often represents the manifestation of side effects, particularly in the placebo arm [5].

The nocebo effect can also be the result of an active medication treatment [6].

According to a recent analysis from 62 randomized trials involving 5.095 patients with PDPN, the nocebo effect in placebo arms contributed to $5.8 \%$ of subject's discontinuations [5]. This is considerable and can lead to adverse events of any kind and varied degrees of severity.

As side effects are often class-related, they are detailed in the label of any investigated comparative study medication. In case of a placebocontrolled study without an active comparator, any information regarding side effects provided to study subjects relate to the assumption that a newly investigational drug, by falling into or close to a certain class of medications, is likely to exert similar side effects.

The nocebo effect is the likely consequence of the psychological impact from certain words focusing only on side effects and their related consequences rather than on an up-front reassuring explanation of the reasons behind these adverse events, including the associated underlying disease and co-morbidities.

Also the misunderstanding that these side effects can be of mild or moderate intensity rather than severe and can ease off during the course of the study may also contribute to generate this nocebo response. Similarly, ambiguity in some written wordings from official documents such as the Informed Consent and the Patient Information Sheet might also contribute to the negative outcome.

As far as the Informed Consent is concerned, it was previously shown how influencing this can be in terms of its impact on the nocebo effect in clinical setting [7-9].

In essence, the nocebo effect derives from the power of some utilized words during the communication between the site staff personnel and the subjects, but also between subjects themselves coming to the site into groups during a study visit and talking to each other. The nocebo effect does not necessarily relate to a deliberate intention of generating negative feelings in subject's mind, but it is simply the unfortunate result of an inappropriate or inaccurate verbal communication.

Typically, explanatory words on study design and study drug related medications are pronounced by site personnel in front of the subject during early screening visit and subsequent study visits. A negative emphasis can be given at any time by using some inappropriate or ambiguous wordings with the effect to easily generate fears in subject's mind, particularly in those more anxious or psychologically more fragile than others, ultimately in those who can easily get worried or

*Corresponding author: Domenico Merante, Senior Director Clinical Development Daiichi Sankyo Development Ltd. Chiltern Place, Chalfont Park, Gerrards Cross Buckinghamshire - SL9 OBG, UK, Tel: 0044 (0) 1753482 802; Fax: 0044 (0) 1753 899 107; E-mail: nmerante@dsd-eu.com

Received September 27, 2013; Accepted November 19, 2013; Published November 24, 2013

Citation: Merante D, Currie A, Feins K (2013) Impact of the Nocebo Effect in Clinical Studies of Painful Diabetic Peripheral Neuropathy and Potential Strategies to Minimize this Effect. J Diabetes Metab 4: 312. doi:10.4172/2155-6156.1000312

Copyright: (C) 2013 Merante D, et al. This is an open-access article distributed under the terms of the Creative Commons Attribution License, which permits unrestricted use, distribution, and reproduction in any medium, provided the original author and source are credited. 
scared of experiencing some of these side effects.

An ethical dilemma still remains on how much detail about study drugs should be provided up front to all participating subjects before and during the clinical study, as well as how to frame these words and their appropriateness of use. Provided the significance and potential severity of the nocebo response in PDPN subjects, it is quite obvious that this challenge cannot be handled by limiting the amount of information around study-related treatments.

We believe that a multi-disciplinary support with a comprehensive training program at each participating study site needs to be put in place, as well as a full educational support to all subjects before and during the study visits. For the scope, an adequate training and educational courses to study subjects become necessary to mitigate the nocebo response. These need to be carried out by experienced and well trained site staff from screening visit onward. Any relevant information related to the study and study treatments should be given in a positive rather than negative frame content and indeed accordingly to Good Clinical Practice and Internal Conference of Harmonization Guidelines [10,11] via the Informed Consent and the Patient Information Sheet.

With respect to the Information Sheet [11], this should contain detailed information of the study medications, including the description of any side effect, which might occur during the course of the study. For any new drug or procedure site personnel needs to objectively explain to the patients all the possible side effects, but with no negative emphasis, threat or concern. If study subjects suffered these or any other symptoms during the clinical study they should report them at the next study visit.

A medically qualified person at the site should also provide a contact name and a telephone hotline that subjects can contact in the event of concerns being raised during the course of the study. The known side effects should be listed in terms the patient will clearly understand their nature and significance. For any relatively new drug it should be also explained that there may be unknown side effects.

In summary, it is clear that any effort to mitigate the nocebo effect needs to focus on training and on education by clarifying all realistic expectations of possible study outcomes [12], and providing clarity of any wording utilized by study site personnel during the consenting process $[12,13]$.

Amongst the several challenges recognized in PDPN clinical research [14,15], an additional one is due to the likelihood of different subject phenotypes, which include, for instance, lack of response to pain medications or a reduced drug responsiveness overtime.

To date, it is recognized that there is lack of evidence that an individual who manifests a nocebo/placebo response to one treatment will manifest a nocebo/placebo response to any other treatment.

In addition, no fixed nocebo/placebo-responding trait or propensities were identified in regard to what was formerly defined by Mc Glashan et al. [16] a "placebo personality". The same applies to the nocebo response. In a carefully designed study looking at the placebo response, Lasagna et al. [17] found that there was no way that any observer could determine, by testing or by interview, which subject would manifest a placebo reaction and which would not.

More recently in other neuropathic pain conditions such as neuropathic pain associated with fibromyalgia [18], the identification of subgroups of patients with different clinical profiles and degrees of depression/anxiety, with low or high or no control over pain, if low or very high catastrophizers, was carried out. Conversely, similar clinical criteria could also support the identification of PDPN subjects who might respond to placebo and/or being more prone to develop a nocebo response [19].

Future research would be relevant in PDPN to identify pain phenotypes [20] and to individualize typology-based treatment criteria of choice. The likely existence of different clinical profiles in patients suffering from this condition supports the need for further research in clarifying this phenomenon.

In summary, clear strategies to understand patient's different phenotypes in order to minimize nocebo effect in both clinical trials and clinical practice in PDPN should be developed [19,20]. Without any strategy put in place by specifically targeting the nocebo response before a clinical study is initiated, this effect remains today a difficult task to mitigate.

An effective strategy to reduce the nocebo effect may allow the improvement of the overall tolerability profile of placebo, as well as of any comparative study active medication. The beneficial impact derived from that attempt can ultimately improve the retention rate of subjects until their completion in clinical studies.

Ultimately, this would help to truly assess the efficacy and safety profile of a new compound being investigated.

\section{Acknowledgments}

Dr Domenico Merante is employed by Daiichi Sankyo Development Ltd. Gerrards Cross, United Kingdom.

Alexander Currie is employed by Daiichi Sankyo Development Ltd., Gerrards Cross, United Kingdom.

Karen Feins is employed by Daiichi Sankyo Pharma Development, Edison, New Jersey, USA.

\section{References}

1. Bril V, England J, Franklin GM, Backonja M, Cohen J, et al. (2011) Evidencebased guideline: Treatment of painful diabetic neuropathy: Report of the American Academy of Neurology, the American Association of Neuromuscular and Electrodiagnostic Medicine, and the American Academy of Physical Medicine and Rehabilitation. Neurology 76: 1758-1765.

2. Tesfaye S, Boulton AJ, Dickenson AH (2013) Mechanisms and management of diabetic painful distal symmetrical polyneuropathy. Diabetes Care 36: 24562465

3. (2013) Guideline on the clinical development of medicinal products intended for the treatment of pain. Draft. European Medicine Agency: 1-21.

4. (2013) A Randomized, Double-Blind, Placebo and Active ComparatorControlled Study of DS-5565 for Treatment of Neuropathic Pain Associated With Diabetic Peripheral Neuropathy. ClinicalTrials.gov processed this record on October 25, 2013 http://clinicaltrials.gov/show/NCT01496365.

5. Häuser W, Hansen E, Enck P (2012) Nocebo phenomena in medicine: their relevance in everyday clinical practice. Dtsch Arztebl Int 109: 459-465.

6. Barsky AJ, Saintfort R, Rogers MP, Borus JF (2002) Nonspecific medication side effects and the nocebo phenomenon. JAMA 287: 622-627.

7. Cohen S (2012) The nocebo effect of Informed Consent. Bioethics.

8. Colloca L, Miller FG (2011) The nocebo effect and its relevance for clinica practice. Psychosom Med 73: 598-603.

9. Miller FG, Colloca L (2011) The placebo phenomenon and medical ethics: rethinking the relationship between informed consent and risk-benefit assessment. Theor Med Bioeth 32: 229-243.

10. European Medicines Agency (2013) ICH Guidelines. Handling of informed consent marketing authorisation applications (products for human use).

11. U.S. Food and Drug Administration (2013) A Guide to Informed Consent Information Sheet Guidance for Institutional Review Boards and Clinical 
Citation: Merante D, Currie A, Feins K (2013) Impact of the Nocebo Effect in Clinical Studies of Painful Diabetic Peripheral Neuropathy and Potential Strategies to Minimize this Effect. J Diabetes Metab 4: 312. doi:10.4172/2155-6156.1000312

Page 3 of 3

Investigators.

12. Faasse K, Petrie KJ (2013) The nocebo effect: patient expectations and medication side effects. Postgrad Med J 89: 540-546.

13. Colloca L, Finniss D (2012) Nocebo effects, patient-clinician communication, and therapeutic outcomes. JAMA 307: 567-568.

14. Häuser W, Bartram-Wunn E, Bartram C, Reinecke H, Tölle T (2011) Systematic review: Placebo response in drug trials of fibromyalgia syndrome and painful peripheral diabetic neuropathy-magnitude and patient-related predictors. Pain 152: $1709-1717$

15. Merante D (2013) Challenges in Painful Diabetic Peripheral Neuropathy clinical research. Oral presentation at the 4th World Congress on Diabetes \& Metabolism, Chicago, August 14-16
16. McGlashan TH, Evans FJ, Orne MT (1969) The nature of hypnotic analgesia and placebo response to experimental pain. Psychosom Med 31: 227-246.

17. Lasagna L, Mosteller F, Von Felsinger JM, Beecher HK (1954) A study of the placebo response. Am J Med 16: 770-779.

18. Giesecke T, Williams DA, Harris RE, Cupps TR, Tian X, et al. (2003) Subgrouping of fibromyalgia patients on the basis of pressure-pain thresholds and psychological factors. Arthritis Rheum 48: 2916-2922.

19. Häuser W, Bartram C, Bartram-Wunn E, Tölle T (2012) Adverse events attributable to nocebo in randomized controlled drug trials in fibromyalgia syndrome and painful diabetic peripheral neuropathy: systematic review. Clin J Pain 28: 437-451.

20. Spallone V, Greco C (2013) Painful and painless diabetic neuropathy: one disease or two? Curr Diab Rep 13: 533-549. 